\title{
Sleep Disturbance Subordinate Domain
}

National Cancer Institute

\section{Source}

National Cancer Institute. Sleep Disturbance Subordinate Domain. NCI Thesaurus. Code C125618.

The collection of PROMIS item scales that assess perceptions of sleep quality, sleep depth, and restoration associated with sleep; perceived difficulties and concerns with getting to sleep or staying asleep; and perceptions of the adequacy of and satisfaction with sleep. 